\title{
EXTENSION OF CREATIVE APPROACHES VISUAL ARTISTS BY AUGMENTED REALITY (AR)
}

\author{
Atanas Markov, a.markov@ts.uni-vt.bg
}

"Cyril and St. Methodius" University of Veliko Tarnovo, Bulgaria

Abstract: There are currently over 3.8 billion smartphone users in the world (Reference from 01.2021). Mobile technologies are becoming an integral part of our lives and this undoubtedly provides a large and diverse environment for the expression of artists from all fields. Mobile technology is changing the way we encounter art. They do it mobile and the term "on demand" is extended to "on the go". The works are becoming more diverse and innovative and every person with a smartphone is a potential user of art. Most modern smart devices are now able to provide Augmented Reality (AR) experiences. AR is already used by innovative brands in trade and marketing, but AR can, and is used, and will be used more and more in the art world. We will no longer associate the visual arts with just visiting art galleries or theater and concert halls. Technologies such as augmented reality (AR), virtual reality (VR), mixed reality (MR) or generalize Extended Reality (XR) open up new creative possibilities for artists and new experiences for the audience. This not only gives new sensations to the audience, but also frees the art from the gallery, thus reaching a completely new audience.

Keywords: Augmented Reality (AR), Interactive Art, Visual Art

\section{РАЗШИРЯЯВАН НА ТВОРЧЕСКИТЕ ПОАХОАИ ПРИ ВИЗУААНИТЕ АРТИСТИ ЧРЕЗ АОБАВЕНА PEAAHOCT (AR)}

Атанас Марков, a.markov@ts.uni-vt.bg

Великотърновски университет „Св. св. Кирил и Методий“, България

Резюме: В момента в света има нал 3,8 милиарда потребители на смарторони (Справка от 01.2021 г.). Мобилните технологии се преврьщат в неразделна част от живота ни и това без сьмнение преАоставя еАна мащабна и различна среда за изява на творци от всякакви области. Мобилните технологии променят начина, по който се сбльскваме с изкуството. Те го правят мобилно и терминьт „при поискване“ ("On demand") се разширява Ао „в Авижение" ("on the go"). 
Произведенията стават все по-разнообразни и иновативни и всеки човек със смартфон е потенциален потребител на изкуство. Повечето от съвременните смарт устройства вече са способни Аа предоставят преживявания с Аобавена реалност (Augmented Reality и^и AR). AR вече се използва от иновативни брандове в областта на тьрговията и маркетинга, но AR може, и се използва, и ще се използва все повече в света на изкуството. Визуалните изкуствата вече няма $а$ г ги свьрзваме само с посещение на художествени галерии или театрални и концертни зали. Технологии като Аобавена реалност (AR), виртуа^ната реалност (VR), смесена реалност (MR) и^и обобщеното разширена реалност (Extended Reality и^и XR) отварят нови творчески възможности преА артистите и нови изживявания за публиката. Това не само Аава нови усещания на аудиторията, но и освобожАава изкуството от преАелите на галерията, като така Аостига и Ао съвсем нова публика.

КАючови Ауми: Аобавена реалност, интерактивно изкУство, ВизуаАни изкУства

В историята межАу науката и изкуството винаги е имало връзка. На моменти по-близка, на моменти по-Аистанцирана. Традиционно те се разбират като Аве различни култури, но възникват и интерАисциплинарни ситуации, за които е необходимо сътрудничество И обмен межау тях. В съвремието най-често това се случва при необхолимостта на визуалните изкуства $А$ с се възползват от компютьрните технологии или обратно, но не само (Kosev, 2009). Могат $\Delta a$ се $\Delta$ алат примери и от областта на театьра, танцовите изкуства, музиката и др. в сътрудничество не само с компютърните технологии, а и с инженерни и математически науки, архитектура, оптика и Ар. От появата на компютрите учените и художниците винаги са намерили общо поле за работа и разбиране (Kosev, 2015). Така с използването на новите технологии разстоянието, което разделя Авете Аисциплини става все по-малко. Анес могат $а$ б бъдат намерени множество примери, при които хуАожниците използват новите технологии в своите артистични произведения. Такива могат да бъдат както интерактивни инсталации, виртуални светове, роботизирани произведения, така и все по често използваните технологии за добавена реалност (AR) (Kosev, 2004). ТАасъкът при разработването на (мулти)меАийно съдьржание през Авалесет и пьрви век съзАава нова орорма на Аигитално изкуство чрез Аобавена реалност (AR) (Azuma, 1997). 
Тази технология оказва влияние вьрху традиционните естетически принципи. В естетическите изследвания се разглежАа същността на естетическите Аейности чрез анализ на художествени произведения. Цифрровата естетика (Jensen, 2007) тук се разбира и анализира като съвкупност от инАивиАуално преживяване и намесата или ненамесата на социалното взаимодействие. По същия начин Аигиталната естетика на AR изкуството (Geroimenko, 2014) се фрокусира върху това как усещаме нашия свят, Аокато взаимодействаме чрез Аобавени възприятия от виртуален свят, слеА което се залейства нашето съзнаване.

За $А$ व се налхвърли очарованието от новата технология и $\mathrm{Aa}$ се приветства концептуалната еволюция, художникьт трябва $А$ може $А$ व работи Аиректно с технологията. Ранните решения за преололяване на тази разлика межАу технологията и художниците и не програмистите вкАючват DART (Designer's Augmented Reality ToolKit), разработен в Технологичния институт в АжорАжия. В статията „DART: A toolkit for rapid design exploration of augmented reality experiences" авторите заявяват, че: „Аизайнерите са най-едективни, когато работят Аиректно със срелата, и че работата чрез посредник сериозно пречи (и^и Аори унищожава) творческият процес." (Maclntyre et. al., 2004). Те илюстрират това твърдение с примера за разликата межлу художник, насочващ асистент

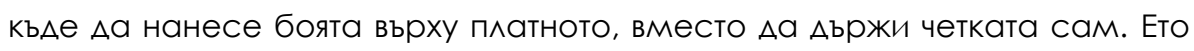
какво споделя Хельн Папаганис (Helen Papagiannis): „Като художник, работещ с AR от 2005 г., открих, че е критично за моята практика $\Delta$ a мога Аа експериментирам и $а$ а работя сьс средата директно, а не чрез посредник като компютьрен програмист (поне пьрвоначално). Това ми позволи $А$ разбера по-Аобре ограниченията и възможностите на технологията, която използвах като отправна точка за илеи. Процесьт при мен включва пьрво изучаване на чертите на технологията, като експериментирам Аиректно със средата, за да разбера какво прави Аобре и какво не толкова Аобре." (Papagiannis, 2010)

Този начин на изследване определя развитието на сьльржанието, като пьрво се създава сценарий, който се Аоразвива от технологията, а не $\Delta$ a се започне с история, която $\Delta$ a се алаптира към технологията. 
Този подхол е критичен при разбирането на новите технологии и прилагането им като изразно средство. СлеА като се разберат възможностите на технологията, експериментирането с нея може $\Delta а я$ въведе в експлоатация за нови форми на естетически изживявания. Разбира се не винаги е възможно всеки автор сам да разбира найновите технологии и Аа борави с тях с лекота. НужАата от високотехнологични специалисти и работата в екип при съзАаването на произведения от този тип, води $А$ разглежАането на тази залача като интерАисциплинарна (Kosev, 2016).

Аобавената реалност не е непозната за артистите технология и могат $\Delta$ a се споменат примери, които я изпо^зват успешно, като: „ARART - Анимирани рисунки" (ARART, 2021). Творците в ARART изпо^зват шедьоври като "Момичето с перлената обица" на Йоханес Вермеер [Фиг. 1], „САънчогледи“ на Винсент Ван Гог и „Мона Аиза" на Аеонардо $\Delta а$ Винчи и ги пренасят в света на AR, като Аобавят виртуално сьАьржание и въвличат участника в еАно „истинско“ преживяване. Така на базата на реалността осъзнаването на произведенията се усилва чрез AR, като Аори налхвърля самата реалност.

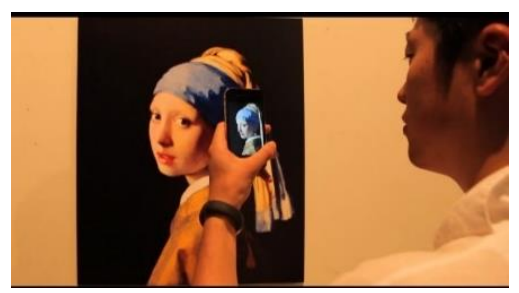

Фиг. 1: ARART - Animate paintings

Аруг интересен пример за AR е проектьт Mirages \& miracles (2017) на арт групата Adrien M \& Claire B (Adrien M \& Claire B, 2021). [Фиг. 2] Това са поредица от инсталации, обитавани от цифров анимизъм. От малки Ао мащабни работи, този набор от инсталации преАлага Аеликатно налагане на виртуалното и материалното, използвайки Аобавени рисунки, холографоски илюзии, виртуална реалност и мащабни проектирания. 


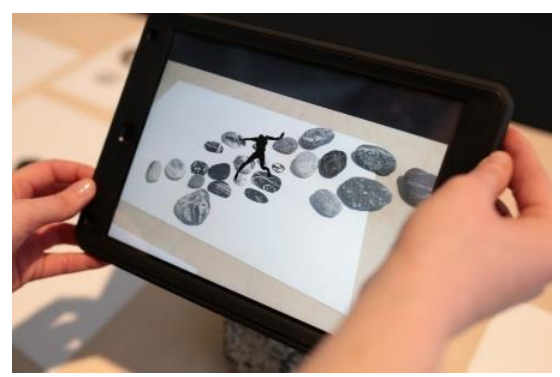

Фиг. 2: Арт група Adrien M \& Claire B - Mirages \& miracles (2017)

Марджан Могадаам (Marjan Moghaddam) е пионер и награжАаван Аигитален художник и аниматор от 80-те години насам. Тя също използва AR в послеАните си инсталации, които често преАставляват анимирани виртуални скулптури [Фиг. 3]. В нейната практика тя използва Аигиталните грешки (glitch), като естетичен и технологичен ореномен и като начин, по който Аигиталното трансорормира и променя фризическото. Така нейните артистични бъгове се противопоставят на съществуващите концепции за женската фрорма в изкуството. В нейните анимирани скулптури се вплитат стройни, пищни, м^аАи, стари, бременни, криви, стилизирани и абстрактни женски фрорми, като съвременен Аигитален подход към представянето на женската фрорма.

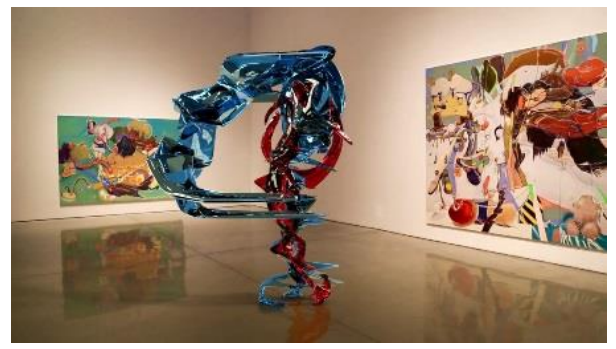

Фиг. 3: Marjan Moghaddam - "Baisser in Mary Boone, in Glassish \& Waxish Glitch"

ШеАьовьрьт на Кристо и Жана-К^оА „Мастаба" [Фиг. 4], в езерото Сърпентайн в Хайд парк в ^онАон също може вече да бъАе наблюАаван с помощта на Аобавена реалност. Посетителите на Хай Парк на практика могат $а$ а визуализират на своите смартфони еАно от найизвестните публични произведения на изкуството. 
Благодарение на безплатното приложение Acute Art (Acute Art, 2021) тази емблематична скулптура се заврьща като точно виртуално копие на реалната скулптура, инсталирана през 2018 г. Пренасянето на „Мастаба" в AR $\triangle$ ава на публиката шанс $\Delta а$ бъАе като художник, поставяйки скулптурата в пейзажите на градините на Кенсингтьн и извън него.

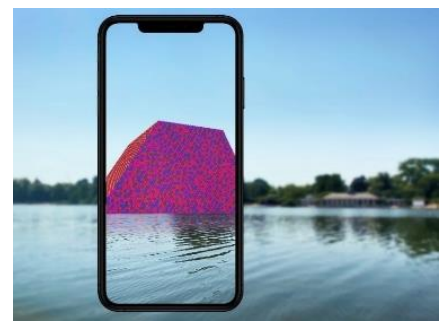

Фиг. 4: Аобавена реалност на произвеАението на Кристо и Жана-КлоА - „Мастаба“

Както се вижАа и от примерите мобилните технологии са в основата на разпространението на тази различна среда за изява. Те се преврьщат в неразделна част от живота ни и това без сьмнение предоставя еАна мащабна и размична възможност за изява на творците. Моби^ните технологии също променят начина, по който се сбльскваме с изкуството. Те го правят мобилно и термина "при поискване" ("On demand") се разширява $А$ „в Авижение" ("оn the gо"). Така произведенията стават все по-разнообразни и иновативни, а всеки човек със смартфон е потенциален потребител на изкуство (Kosev, 2010a), (Kosev, 2010b). Мобилните технологии съвместно с AR Аават възможност за интеракции на едно ново мулти-пространствено ниво. СпореА Менг Kю (Meng Qu) този виА взаимодействия има следните пет основни характеристики (QU, 2017):

1) Аиверсификация на начина на интеракция;

2) моби^ност, представляваща възможността за използване на мобилна AR на всяко място;

3) интерактивност в реално време;

4) многопосочното взаимолействие межАу участник, мобилното изчислително Устройство и фризическата среАа;

5) уникаАни инАивиАуални преживявания. 
Събитие с мулти-пространствена интеракция в реално време може $\Delta$ а се третира и като начин за получаване на естетически преживявания в пространство с Аобавена реалност. На базата на това проучване и на натрупания опит в съвместната работа с Аоц. А-р Светослав Косев в областта на интерактивни, генеративни и компютърно полпомогнати произведения на изкуството ще се реализират серия от AR инсталации. [Фиг. 5] Те са естествено продьлжение на съвместната ни работа представена в арт групата Co-interaction (http://www.cointeraction.com), които се планира $\Delta а$ бъдат експонирани в началото на юни 2021 в галерия „Аоза“ - Софрия.

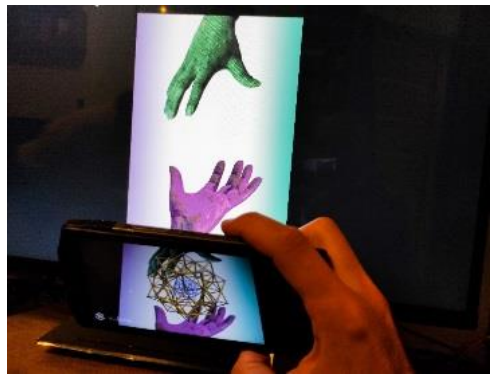

\section{Фиг. 5: Прототип на еAна от AR инсталациите проектирани} съвместно от Атанас Марков и Светослав Косев

AR ce използва, и ще се използва все повече в света на изкуството, като отваря нови творчески възможности пред артистите и нови изживявания за публиката (Kosev, 2013). Това не само дава нови усещания на аудиторията, но и освобожАава изкуството от пределите на галерията, като така Аостига и Ао съвсем нова публика.

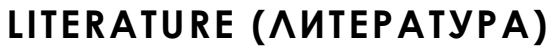

Acute Art. (2021). Virtual Reality \& Augmented Reality Art Production - Acute Art, Извлечено от https://acuteart.com/ (Viewed at 23-03-2021)

Adrien M \& Claire B. (2021). Mirages \& miracles - Adrien M \& Claire В, Извлечено от Mirages \& miracles: https://www.am-cb.net/en/projets/mirages-miracles (Viewed at 23-03-2021)

ARART. (2021). APART, Извлечено от http://arart.info (Viewed at 23-03-2021)

Azuma, R. T. (1997). A survey of augmented reality. Presence: Teleoperators and virtual environments, 6(4), 355-385. 
Blair Maclntyre, Maribeth Gandy, Steven Dow and Jay David Bolter. (2004). DART: A toolkit for rapid design exploration of augmented reality experiences. Conference on User Interface Software and Technology (UIST'04), (стр. 197). Sante Fe, New Mexico.

Geroimenko, V. (. (2014). Augmented reality art: From an emerging technology to a novel creative medium. Springer, 313-314.

Jensen, K. B. (2007). Mixed media: from digital aesthetics towards general communication theory. Northern Lights: Film \& Media Studies Yearbook, 5(1), 7-24.

Kosev, S. (2013). Creative processes in electronic graphics., Collection. (in Bulgarian). ISBN 978-954524-981-5, [Косев С. (2013). Творчески процеси в електронната графика., Сборник. ].

Kosev, S. (2004). Three-dimensional technologies in graphic design and application in multimedia products., Collection. (in Bulgarian). ISBN 954-524-409-7 29. Косев, С. Тримерни технологии в графричния Аизайн и приложението им в мултимедийните продукти., Сборник.

Kosev, S. (2009). A Training Model of a 3D computer graphics., Collection. (in Bulgarian). ISBN 978954-350-084-0. Сборник. Научна конореренция. Съвременно образование и чужА език. Астарта.

Kosev, S. (2010a). Perspective, perspective system and three-dimensional graphics., Monograph. (in Bulgarian). ISBN 978-954-07-3022-6. [Косев С. (2010). Перспектива, перспективна система и триизмерна графика., Монографиия. ].

Kosev, S. (2010b). Perspective. Design, implementation and application through three-dimensional computer graphics, Monograph. (in Bulgarian). ISBN 978-954-07-3020-2. [Косев С. (2010). Перспектива. Проектиране, реализация и приложение чрез триизмерната компютьрна графрика, Монографияя. ].

Kosev, S. (2015). Multimedia, as a form of interaction between art and technology, International Scientific Conference "From the sensory to the visual - pluralism in art" (in Bulgarian). ISBN 978-619-208-103-4, [Косев С. (2015). Мултимедията, като форма на взаимодействие межАу изкуството и технологията, МежАународна научна конфреренция "От сетивното към визуалното плурализмьт в изкуството"].

Kosev, S. (2016). Technological means as a form of creative expression - teamwork, aesthetics, interaction, interlude; International Scientific Conference "From the Sensory to the Visual Pluralism in Art" (in Bulgarian). ISBN 978-619-208-141-6, [Косев С. (2016). Технологичните средства като фрорма на творческа изява - екипност, естетика, интеракция, интермедия; МежАународна научна конфреренция "От сетивното към визуалното - плурализмьт в изкуството"].

Papagiannis, H. (2010). 'Wonder Turner' and 'The Amazing Cinemagician' augmented reality and mixed reality art installations. 2010 IEEE International Symposium on Mixed and Augmented Reality (ISMAR)—Arts, Media, and Humanities (ISMAR-AMH), (стр. 27-32). Seoul, South Korea.

Qu, M. (2017). The Aesthetic Experience of Augmented Reality Art. ISEA 2017 Bio-creation and Peace, 23rd International Symposium on Electronic Arts: Manizales, (стр. 79-85). Colombia.

ATANAS MARKOV

PhD, Assist. Prof.

"St. Cyril and St. Methodius" University

Veliko Tarnovo, Bulgaria 

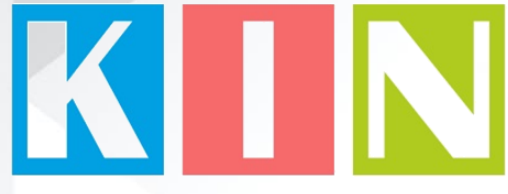

\section{ISSN: 2367-8038}

\section{Съставители \\ Петко Ст. Петков \\ Галина БогАанова}

Материалите в сборника са обект на авторско право. Разрешава се безвъзмезАното ползване на техни електронни/ хартиени копия само за мична употреба или обучение, при пьлно цитиране на текущата страница и слеА писмена Аек^арация от цитиращия за ^ипса на търговски намерения.

Научната поредица е регистрирана в НАЦИА С № 1209

() Авторски колектив, 2021

Техническо реАактори: Калина Сотирова-Вълкова Николай Ноев Паска^ Пиперков

\section{Editors}

Petko St. Petkov

Galina Bogdanova

This work is subject to copyright.

Open and free of charge use of digital/hard copies of publications is granted only for personal or educational use, with full citation of the current page, and after written declaration of the quoting side for notcommercial Intention.

Science series has been registered in NACID with No. 1209

() Authors` Group, 2021

Technical editors:

Kalina Sotirova-Valkova

Nikolay Noev

Paskal Piperkov

\section{ISSN: 2367-8038}

том 7, брой $1(10) / 2021$

vol. 7 , issue $1(10) / 2021$ 